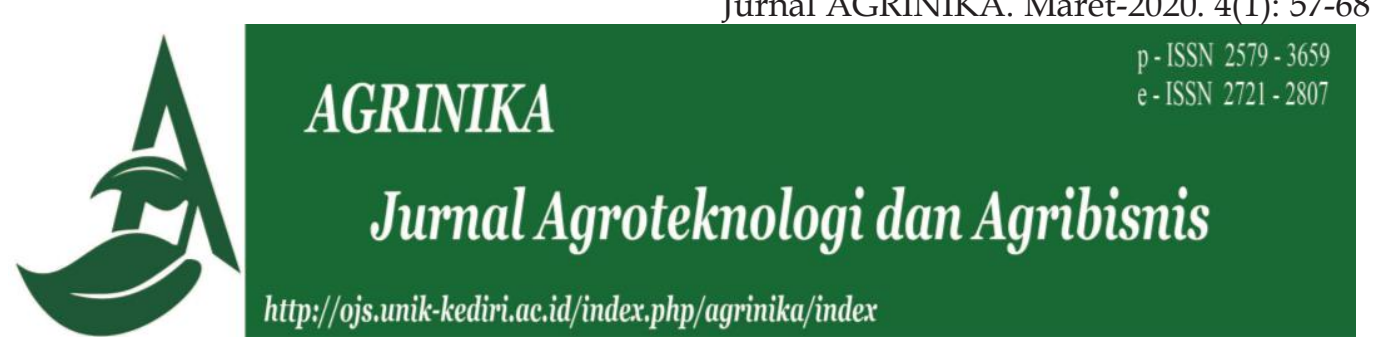

\title{
Analisis Kelayakan Usaha Tiwul Instan di Desa Suren Kecamatan Bendungan Kabupaten Trenggalek
}

\author{
Agustia Dwi Pamujiati ${ }^{1 *}$, Ahmad Haris Hassanudin Slamet ${ }^{2}$, Wim Ambawati ${ }^{3}$ \\ ${ }^{1}$ Fakultas Pertanian, Universitas Kadiri, Kediri, Indonesia \\ ${ }^{2}$ Fakultas Ekonomi dan Bisnis Islam, Institut Agama Islam Negeri Ponorogo, Ponorogo \\ Indonesia \\ ${ }^{3}$ Fakultas Teknologi Pertanian, Universitas Jember, Jember, Indonesia \\ *Korespondensi: tinaagustia@unik-kediri.ac.id
}

Diterima 27 Januari 2020/Direvisi 28 Februari 2020/Disetujui 11 Maret 2020

\begin{abstract}
ABSTRAK
Tiwul instan mempunyai prospek bisnis yang cukup menjanjikan dengan berbagai macam cita rasa yang berbeda. salah satu daerah yang memproduksi tiwul instan yaitu Kecamatan Bendungan Kabupaten Trenggalek. Tujuan penelitian ini untuk mengetahui biaya dan pendapatan serta kelayakan usaha tiwul instan yang sudah dikembangkan di Kecamatan Bendungan Kabupaten Trenggalek. Metode penelitian ini menggunakan analisis deskripstif dan kualitatif. Parameter pengamatan yang diamati yaitu biaya produksi, penerimaan, Net Present Value, IRR, Net B/C Ratio, dan BEP. Hasil penelitian menunjukkan bahwa biaya produksi usaha pengolahan singkong menjadi tiwul instan sebesar Rp. 445.430/proses produksi dengan kapasitas produksi $170 \mathrm{~kg}$ bahan baku singkong dan menghasilkan $100 \mathrm{~kg}$ tiwul instan. Penerimaan yang didapat dari usaha tiwul instan sebesar Rp. 650.000 dan pendapatan sebesar Rp. 204.570 per satu kali proses produksi. Jumlah BEP produksi sebanyak $69 \mathrm{~kg}$, sedangkan BEP harga sebesar Rp. 4.551/kg. Tingkat kelayakan usaha pengolahan tiwul instan di Desa Suren Kecamatan Bendungan Kabupaten Trenggalek menguntungkan dan layak diusahakan karena memiliki nilai NPV positif (43.948.219), nilai IRR lebih besar $(33,10 \% /$ tahun) daripada suku bunga bank (12\%/tahun), dan memiliki nilai Net B/C ratio lebih dari 1 $(1,62)$.
\end{abstract}

Kata kunci: Kelayakan usaha; Penerimaan; Tiwul instan

\section{ABSTRACT}

The business prospect of instant tiwul prospects has recently been promising, as different kind of aroma and flavors of the product being developed. One of the areas producing instant tiwul is Trenggalek Regency. The purpose of this research was to analyse the cost and income as well as business feasibility of instant tiwul in Bendunan District, Trenggalek Regency. The methodology employed in this research was descriptive and qualittive for the analysis. Parameters observed in this research included production costs, revenue, net prsent value, IRR, net $\mathrm{B} / \mathrm{C}$ ratio, and BEP. The research results showed that production costs of cassava processing to instant tiwul was IDR 445.430 / production process of with production capacity of $170 \mathrm{~kg}$ of raw material cassava producing instant tiwul of $100 \mathrm{~kg}$. The revenue was IDR 650.000 and income of IDR 204.570 per production process. The BEP unit was $69 \mathrm{~kg}$ and BEP of price was IDR $4.551 \mathrm{~kg}$. The feasibility of instant tiwul processing enterprises in the district was profitable and worthy for having provide the NPV of 43.948.219, the IRR was larger than 
bank rate $(33,10 \%$ / year and $12 \% /$ year $)$, and having the Net B/C Ratio more than 1 of 1.62

Keywords: Financial feasibility; Instant tiwul; Revenue

\section{PENDAHULUAN}

Singkong merupakan salah satu tanaman pangan yang cukup penting setelah padi dan jagung. Singkong dapat dibudidayakan pada lahan kering, mudah dalam perawatannya, serta minim usaha taninya. Hal ini menyebabkan banyak petani yang menanamnya khususnya di lahan kering (Akbar \& Febriani, 2019).

Salah satu daerah dengan kondisi tanah kering yaitu Kabupaten Trenggalek. Produksi singkong di Kabupaten Trenggalek cukup tinggi yaitu mencapai 244.537 ton (Badan Pusat Statistik Jawa Timur, 2017). Tingginya produktivitas singkong menjadi potensi untuk diolah menjadi produk dengan nilai ekonomi tinggi.

Produk olahan singkong yang sedang banyak dikembangkan yaitu tiwul. Pada zaman dahulu tiwul belum tersedia dalam bentuk instan., namun kini sudah tersedia tiwul instan yang dapat dikonsumsi kapan saja serta dapat disimpan dalam waktu yang lama (Suhardi \& Suharjo, 2006). Hal ini merupakan terobasan baru sehingga tiwul lebih praktis, siap saji, dan mudah didapat.

Adanya alasan tersebut menjadikan Kecamatan Bendungan Kabupaten Trenggalek tertarik untuk mengembangkan agroindustri tiwul instan. Selain itu, didukung juga oleh ketersediaan lahan, bahan baku dan tenaga kerja yang melimpah.

Peran industri dalam suatu proses produksi sangat perlu, tidak hanya sebagai alat untuk menghasilkan atau memperluas keragaman produk hasil agroindustri, tetapi juga sebagai faktor penentu daya saing dalam bentuk kinerja produknya dan sebagi penyumbang dalam meningkatkan nilai tambah.

Dengan adanya kegiatan industri yang mengubah bentuk primer menjadi produk baru yang lebih tinggi nilai ekonomisnya setelah melalui proses pengolahan, maka akan dapat memberikan nilai tambah karena dikeluarkan biaya-biaya sehingga terbentuk harga baru yang lebih tinggi, diminati konsumen dan akan mendapatkan keuntungan yang lebih besar.

Tiwul instan mempunyai prospek bisnis yang cukup menjanjikan dengan berbagai macam cita rasa yang berbeda, hal ini dapat dilihat dari adanya peningkatan permintaan tiwul instan yang cukup banyak. Peluang bisnis dapat dimanfaatkan dengan adanya dukungan dari beberapa pihak dari produksi sampai pemasaran sehingga didapatkan sesuatu hasil yang memuaskan. Potensi ini diharapkan mampu menyerap tenaga kerja pedesaan yang banyak karena jumlah tenaga kerja di Kabupaten Trenggalek yang tidak sedikit jumlahnya dan lokasi agroindustri yang masih berdekatan dengan lahan usahatani, tidak menutup kemungkinan adanya peningkatan pendapatan dengan potensi yang dimiliki oleh Kabupaten Trenggalek.

Dengan potensi yang dimiliki oleh Kabupaten Trenggalek mempunyai prospek untuk pengembangan usaha lebih lanjut sebagai sentra agribisnis tiwul instan dengan beraneka cita-rasa dan menjadi ciri khas Kecamatan Bendungan Kabupaten Trenggalek serta diharapkan menjadi sumber 
perkembangan ekonomi regional dan dapat menambah pendapatan rumah tangga, sehingga menjadikan keluarga yang sejahtera.

Namun, belum diketahui biaya dan pendapatan serta kelayakan usaha tiwul instan yang sudah dikembangkan di Kecamatan Bendungan Kabupaten Trenggalek sehingga perlu dilakukan penelitian lebih lanjut. Tujuan penelitian ini untuk mengetahui biaya, pendapatan, dan kelayakan usaha tiwul instan.

\section{BAHAN DAN METODE}

Metode Penentuan Daerah Penelitian

Penentuan daerah penelitian dilakukan secara purposif (Dwiastuti, 2017) di Desa Suren Kecamatan Bendungan Kabupaten Trenggalek. Desa tersebut dipilih karena terdapat pengusaha tiwul instan.

\section{Metode Penarikan Sampel}

Metode penarikan sample yang dilakukan yaitu metode penarikan sampel sensus. Besar sampel yang diambil adalah pengusaha agroindustri pengolahan tiwul instan dari seluruh populasi.

\section{Metode Pengumpulan Data}

Data primer diperoleh melalui metode interview bebas terpimpin dengan menggunakan kuesioner pada setiap anggota sampel. Data sekunder diperoleh melalui pencatatan langsung data-data di kantor Kepala Desa, Kantor Camat dan Kantor Dinas Pertanian Tanaman Pangan Kabupaten Trenggalek.

\section{Metode Pengolahan dan Analisis Data}

Analisis data dilakukan dengan cara kualitatif dan kuantitatif. Data kualitatif dianalisis secara deskriptif, sedangkan data kuantitatif dianalisis menggunakan rumus perhitungan untuk mengetahui biaya usaha dan penerimaan sehingga dapat diketahui tingkat pendapatan dari usaha pengolahan singkong menjadi tiwul instan dalam satu periode.

\section{Analisis Biaya Produksi}

Menurut (Lambajang, 2013) menjelaskan bahwa total biaya atau total cost (TC) adalah jumlah dari biaya tetap atau fixed cost (FC) dan biaya tidak tetap atau variable cost (VC). Pernyataan tersebut dapat dirumuskan sebagai berikut.

$\mathrm{TC}=\mathrm{FC}+\mathrm{VC}$

Dimana

TC :total biaya (total cost)

FC :biaya tetap (biaya penyusutan)

VC :biaya tidak tetap (biaya bahan baku + tenaga kerja)

\section{Penerimaan}

Penerimaan usaha adalah perkalian antara produksi yang diperoleh dengan harga jual (Lambajang, 2013). Hal tersebut dapat dinyatakan dalam rumus sebagai berikut.

$\mathrm{TR}=\mathrm{P} \times \mathrm{Q}$

Dimana

TR : total penerimaan (total revenue)

$P$ : harga

Q :produksi yang diperoleh dalam suatu usaha

\section{Pendapatan}

Menurut (Soekartawi, 2006) pendapatan usaha adalah selisih antara penerimaan dengan seluruh biaya. Hal tersebut dapat dinyatakan dalam rumus sebagai berikut:

$\pi=\mathrm{TR}-\mathrm{TC}$

Dimana:

$\pi$ : pendapatan usahatani

TR : total penerimaan (total revenue)

TC : total biaya (total cost) 
Menurut (Soekartawi, 2006) dalam banyak hal jumlah TC atau total biaya ini selalu lebih besar bila analisis ekonomi yang dipakai dan selalu lebih kecil bila analisis finansial yang dipakai.

\section{Kelayakan}

\section{Net Present Value (NPV)}

Net Present Value merupakan selisih antara benefit (penerimaan) dengan cost (pengeluaran) (Mardliyah \& Supriyadi, 2018). Rumus NPV dapat dilihat dibawah ini.

$$
\mathrm{NPV}=\sum_{\mathrm{i}=1}^{\mathrm{n} B \mathrm{t}}-\mathrm{Ct}
$$

Kriteria NPV :

(1). NPV $>0$, berarti untung

(2). $N P V<0$, berarti rugi

(3). NPV $=0$, berarti Impas (tambahan manfaat yang diterima sama dengan tambahan biaya yang dikeluarkan).

2. Net Benefit/Cost Ratio (Net B/C rasio)

Net B/C Rasio merupakan perbandingan antara benefit bersih dengan biaya bersih (Elvani, 2015). Rumus Net B/C ratio dapat dilihat dibawah ini.

$$
\text { Net B/C rasio }=\frac{\sum_{t=1}^{n} \frac{B t}{(1+i) t}}{\sum_{t=1}^{n} \frac{C t}{(1+i)} t}
$$

Kriteria Net B/C Ratio, yaitu:

(1) Net B/C Rasio > 1, berarti usahatani menguntungkan

(2) Net B/C Rasio < 1, berarti usahatani tidak menguntungkan

(3) Net $B / C$ Rasio $=1$, berati usahatani pada kondisi impas (penerimaan = pengeluaran), atau terjadinya Break Event Point (BEP)

\section{Internal Rate of Return (IRR)}

IRR menunjukkan kemampuan suatu proyek untuk menghasilkan suatu returns atau tingkat keuntungan yang akan dicapainya (I \& Playen, 2019). IRR sebagai pedoman tingkat bunga bank (i) yang berlaku, walaupun sebetulnya bukan i, tetapi IRR akan selalu mendekati besarnya i tersebut. Rumus IRR dapat dilihat dibawah ini.

$$
I R R=l^{\prime}+\frac{N P V}{N P V^{\prime}+N P V^{\prime \prime}}\left(i^{\prime}-i^{\prime \prime}\right)
$$

\section{Dimana:}

$$
\begin{array}{ll}
\text { Bt } & \text { : penerimaan tahun ke t } \\
\text { Ct } & \text { : pengeluaran tahun ke t } \\
\text { I' } & \text { : tingkat bunga yang } \\
& \text { menghasilkan NPV positif } \\
\text { I“ } & \text { : tingkat bunga yang } \\
& \text { menghasilkan NPV negetif } \\
\text { NPV' } & \text { : NPV positif } \\
\text { NPV“ } & \text { : NPV negatif } \\
\text { NPV'+NPV““ } & \text { : merupakan penjumlahan } \\
& \text { mutlak }
\end{array}
$$

Kriteria IRR:

IRR > Sosial Discount Rate, berarti usahatani layak

IRR < Sosial Discount Rate, berarti usahatani tidak layak

\section{Break Even Point (BEP)}

Analisis Break Even Point adalah suatu metode yang mempelajari hubungan antara biaya, keuntungan, dan volume penjualan atau produksi. BEP digunakan untuk mengetahui tingkat kegiatan minimal yang harus dicapai, dimana pada tingkat tersebut perusahaan tidak mengalami keuntungan maupun kerugian (Utami \& Adita, 2019). Ada dua jenis perhitungan BEP, yaitu BEP volume dan BEP harga produksi yang dirumuskan sebagai berikut.
a) BEP Volume Produksi $=\frac{\text { Total biaya }}{\text { Harga ditingkat petani }} \times 1 \mathrm{Kg}$
b) BEP Harga Produksi $=\frac{\text { Total biaya }}{\text { Total Produksi }} \times$ Rp. 
HASIL DAN PEMBAHASAN

Karakteristik Responden Pengolah Tiwul $\underline{\text { Instan }}$

Karakteristik adalah gambaran informasi mengenai keadaaan dalam perusahaan pengolahan ubikayu menjadi tiwul instan di lokasi penelitian. Hal ini diperlukan untuk mengetahui halhal yang berkaitan dengan kemampuan mengadopsi teknologi dalam pengembangan produksi tiwul instan yang selama ini telah dilaksanakan (Putri, 2020). Sebagian besar pengolah tiwul instan dilokasi penelitian merupakan usaha sampingan, karena sebagai pekerjaan utama adalah petani maupun pegawai negeri. Usaha agroindustri ini pada umumnya dikerjakan oleh wanita (ibu rumah tangga), demikian juga dengan tenaga kerja yang digunakan sebagian besar adalah wanita, sehingga usaha ini masih cenderung menjadi pekerjaan sampingan saja. Meskipun usaha ini merupakan usaha sampingan tetapi pendapatan yang diperoleh cukup menjanjikan. Status pekerjaan responden pengolah tiwul instan dalam penelitian dapat dilihat pada Tabel 1.

Tabel 1. Status pekerjaan pengolah tiwul instan di Desa Suren, Kecamatan Bendungan, Kabupaten Trenggalek Tahun 2019.

\begin{tabular}{cccc}
\hline No & Status Pekerjaan & $\begin{array}{c}\text { Jumlah } \\
\text { (orang) }\end{array}$ & Persentase (\%) \\
\hline 1. & Pekerjaan utama & 1 & 20,00 \\
2. & Pekerjaan Sampingan & 4 & 80,00 \\
\hline & Jumlah & 5 & 100,00 \\
\hline
\end{tabular}

Sumber: Data primer diolah tahun 2019

Tabel 1. menunjukkan bahwa sebagian besar responden menjadikan usaha tiwul instan ini sebagai usaha sampingan bukan usaha utama. Hal ini dapat dilihat sebanyak $80 \%$ responden sebagai pekerjaan sampingan. Sebagian besar penduduk Desa Suren bekerja sebagai buruh tani sebanyak $24,70 \%$ dan petani pengusaha sebanyak $17,01 \%$. Petani pengusaha yang dimaksud yaitu petani yang juga mengolah singkong menjadi tiwul instan. Jadi pekerjaan utamanya yaitu petani dan pekerjaan sampingannya adalah produsen tiwul instan.

Berdasarkan jenis kelamin, pengolah/produsen tiwul instan dapat dilihat pada Tabel 2.

Tabel 2. Pengolah ubikayu menjadi tiwul instan berdasarkan jenis kelamin di Desa Suren Kecamatan Bendungan Kabupaten Trenggalek

\begin{tabular}{cccc}
\hline No & Jenis Kelamin & $\begin{array}{c}\text { Jumlah } \\
\text { Responden }\end{array}$ & Persentase (\%) \\
\hline 1 & Laki-laki & 1 & 20,00 \\
2 & Perempuan & 4 & 80,00 \\
\hline Total & & 5 & 100,00 \\
\hline
\end{tabular}

Sumber: Data primer diolah tahun 2019

Dari Tabel 2. dapat dijelaskan bahwa kebanyakan responden sebagai pemilik usaha adalah wanita dengan prosentasi sebesar $80 \%$. Demikian juga dengan tenaga kerja yang digunakan dalam pengolahan ubikayu menjadi 
tiwul instan sebagian besar adalah tenaga kerja wanita. Hal ini sesuai dengan penelitian (Mahendra, 2014) yang menyatakan bahwa dalam suatu agroindustri mayoritas pekerja yang bekerja adalah perempuan.

Menurut (Mulyadi, 2003), tenaga kerja adalah penduduk dalam usia kerja (berusia 15-64 tahun) atau jumlah seluruh penduduk dalam suatu negara yang dapat memproduksi barang dan jasa jika ada permintaaan terhadap tenaga mereka,dan jika mereka mau berpartisipasi dalam aktivitas tersebut

Sedangkan (E. Herawati, 2008) berpendapat bahwa tenaga kerja merujuk pada kemampuan manusiawi yang dapat disumbangkan untuk memungkinkan dilakukannya produksi barang-barang dan jasa-jasa. Sehingga dapat di simpulkan bahwa tenaga kerja adalah penduduk dalam usia kerja (berusia 15-64 tahun) atau

tiap orang yang mampu melakukan pekerjaan, baik di dalam maupun di luar hubungan kerja guna menghasilkan jasa atau barang untuk memenuhi kebutuhan masyarakat.

Menurut (Mahayasa \& Yuliarmi, 2018) permintaan tenaga kerja berkaitan dengan jumlah tenaga kerja yang dibutuhkan oleh perusahaan atau instansi tertentu. Menurut (Turere,
2013), permintaan determinasi permintaan tenaga kerja, yaitu tingkat upah, teknologi, produktivitas, kualitas tenaga kerja, fasilitas modal.

Faktor produksi tenaga kerja merupakan faktor produksi yang penting untuk diperhatikan dalam proses produksi dalam jumlah yang cukup, bukan saja dilihat dari tersedianya lapangan kerja tetapi juga kualitas dan macam tenaga kerja

(Winarsih et al., 2014).

Dalam penghitungan upah yang dibutuhkan dalam pengolahan tiwul instan maka perlu dilakukan konversi ke jumlah HOK. Adapun ketetapan HOK di dalam usahatani adalah 8 jam, sedangkan ditempat penelitian hari kerja per hari adalah 6 jam, sehingga satu hari kerja setara dengan $6 / 8=0,75 \mathrm{HOK}$ dengan upah per hari sebesar $\mathrm{Rp}$. 15.000,-. Dengan demikian apabila upah tenaga kerja per hari dikonversikan ke upah per HOK, maka upah tenaga kerja ditempat penelitian ditetapkan dalam $1 \mathrm{HOK}$ sebesar Rp. $20.000,00$.

Berdasarkan kelompok umur, produsen tiwul instan dapat dibedakan menjadi 3 kelompok umur. Kelompok umur produsen tiwul instan dapat dilihat pada Tabel 3.

Tabel 3. Pengolah tiwul instan berdasarkan kelompok umur di Desa Suren Kecamatan Bendungan Kabupaten Trenggalek

\begin{tabular}{cccc}
\hline No & Kelompok Umur & Jumlah Responden & Persentase (\%) \\
\hline 1. & $36-40$ & 1 & 20,00 \\
2. & $41-45$ & 2 & 40,00 \\
3. & $46-50$ & 2 & 40,00 \\
\hline & Total & 5 & 100,00 \\
\hline
\end{tabular}

Sumber: Data primer diolah tahun 2019

Berdasarkan Tabel 3. dapat diketahui bahwa jumlah pengolah/ pemilik usaha tiwul instan yang paling banyak adalah kisaran umur 41-50. Hal 
ini menunjukkan bahwa kebanyakan pengolah masih tergolong produktif pada usia tersebut dalam segi tenaga, pikiran dan pengalaman dalam pengolahan.

Usia produktif seorang pekerja berkisar antara 15-64 tahun. Pada usia tersebut seseorang masih memiliki tenaga yang baik sehingga akan mempengaruhi produktivitasnya dalam bekerja (N. Herawati, 2013).

Usia tenaga kerja cukup menentukan keberhasilan dalam melakukan suatu pekerjaan, baik sifatnya fisik maupun non fisik. Pada umumnya, tenaga kerja yang berumur tua mempunyai tenaga fisik yang lemah dan terbatas, sebaliknya tenaga kerja yang berumur muda mempunyai kemampuan fisik yang kuat (Riyanto, 2001).

Menurut Badan Pusat Statistik penduduk yang berpotensi sebagai modal dalam pembangunan yaitu penduduk usia produktif atau yang berusia 15-64 tahun.

Dari segi pendidikan, produsen tiwul instan dapat dibedakan menjadi 3 golongan. Golongan produsen tiwul instan berdasarkan umur dapat dilihat pada Tabel 4

Tabel 4. Pengolah tiwul instan berdasarkan tingkat pendidikan di Desa Suren, Kecamatan Bendungan, Kabupaten Trenggalek.

\begin{tabular}{clcc}
\hline No & Tingkat Pendidikan & Jumlah Responden & Persentase (\%) \\
\hline 1. & SD & 1 & 20,00 \\
2. & SLTP & 3 & 60,00 \\
3. & SLTA & 1 & 20,00 \\
\hline \multicolumn{2}{l}{ Total } & 5 & 100,00 \\
\hline
\end{tabular}

Sumber: Data primer diolah tahun 2019

Berdasarkan Tabel 4. maka dapat dilihat bahwa pendidikan responden cukup bervariatif mulai dari berpendidikan SD sebanyak 1 orang dengan persentase $20 \%$, berpendidikan SLTP 3 orang dengan persentase $60 \%$, dan berpendidikan SLTA 1 orang dengan persentase 20\%. Dengan demikian pendidikan dari responden yang terbanyak adalah berpendidikan SLTP.

Kondisi ini didukung oleh kurang meratanya kesempatan bagi sebagian penduduk dalam mengakses pendidikan di Desa Suren Kec. Bendungan Kab. Trenggalek. Padahal pendidikan merupakan salah satu hal yang memampukan masyarakat bersaing dalam dunia kerja, karena diharapkan dengan semakin tinggi pendidikan seseorang, maka produktivitas orang tersebut juga semakin tinggi (Mahendra, 2014).

Selain itu, semakin tinggi pendidikan seseorang, maka akan mudah menerima informasi dalam bentuk apapun. Selan itu, seseorang yang memiliki pendidikan tinggi lebih mudah berkomunikasi (Mahendra, 2014).

Untuk meningkatkan produktivitas para tenaga kerja, maka diperlukan penghargaan serta pengakuan keberadaan para tenaga kerja tersebut. Salah satu cara memberikan penghargaan terhadap prestasi kerja karyawan yaitu dengan melalui upah. Upah merupakan masalah yang menarik dan penting bagi perusahaan, karena upah mempunyai pengaruh yang sangat 
besar terhadap pekerja. Apabila upah yang diberikan oleh perusahaan di rasa sudah sesuai dengan jasa atau pengorbanan yang diberikan maka karyawan akan tetap bekerja dan lebih giat dalam bekerja

\section{Biaya Produksi}

Biaya produksi merupakan biaya yang dikeluarkan oleh perusahaan dalam proses produksi. Biaya terdiri atas biaya tetap (fixed cost) dan biaya variabel (variable cost). Biaya tetap (fixed cost) yaitu biaya yang dikeluaran selama proses produksi dan jumlahnya tidak dipengaruhi oleh banyaknya produksi yang dihasilkan (Lambajang, 2013). Dalam penelitian ini, yang termasuk kedalam biaya tetap adalah biaya penyusutan peralatan. Biaya tetap pengolahan tiwul instan dapat dilihat pada Tabel 5.

Tabel 5. Rata-rata biaya penyusutan peralatan pengolahan tiwul instan di Desa Suren Kecamatan Bendungan Kabupaten Trenggalek

\begin{tabular}{|c|c|c|c|c|c|c|}
\hline No. & Uraian & $\begin{array}{c}\text { Volume } \\
\text { (buah) }\end{array}$ & $\begin{array}{c}\text { Harga } \\
\text { Satuan } \\
(R p)\end{array}$ & $\begin{array}{c}\text { Jumlah } \\
\text { (Rp) }\end{array}$ & $\begin{array}{c}\text { Umur } \\
\text { Ekonomi } \\
\text { (Th) }\end{array}$ & $\begin{array}{l}\text { Penyusutan } \\
\text { (Rp/bln) }\end{array}$ \\
\hline 1. & Pisau & 17 & 5.500 & 93.500 & 3 & 2.597 \\
\hline 2. & Baskom & 14 & 5.000 & 70.000 & 2 & 2.917 \\
\hline 3. & Tampah & 9 & 12.500 & 110.000 & 1 & 9.167 \\
\hline 4. & Girik & 6 & 7.250 & 43.500 & 1 & 3.625 \\
\hline 5. & Rak penjemur & 16 & 25.000 & 410.000 & 2 & 17.083 \\
\hline 6. & $\begin{array}{l}\text { Panci } \\
\text { pengukus }\end{array}$ & 3 & 125.000 & 425.000 & 3 & 11.806 \\
\hline 7. & Panci & 5 & 60.000 & 288.000 & 3 & 8.000 \\
\hline 8. & Ayakan & 6 & 4.500 & 27.000 & 2 & 1.163 \\
\hline 9. & $\begin{array}{l}\text { Alat } \\
\text { pengering }\end{array}$ & 2 & 250.000 & 350.000 & 10 & 3.333 \\
\hline \multirow[t]{2}{*}{10.} & $\begin{array}{l}\text { Mesin } \\
\text { penggiling }\end{array}$ & 1 & 2.500 .000 & 2.500 .000 & 15 & 13.889 \\
\hline & Jumlah & & & 4.367 .900 & & 73.580 \\
\hline
\end{tabular}

Sumber: Data primer diolah tahun 2019

Tabel 5. menunjukkan bahwa rata-rata biaya tetap pengolahan tiwul instan yang harus dikeluarkan untuk penyusutan peralatan sebesar Rp. 73.580,- per bulan. Selain biaya tetap, ada juga biaya variabel.

Biaya variabel merupakan biaya yang dikeluarkan untuk proses produksi tiwul instan yang besarnya dipengaruhi jumlah produksi (Utami \& Adita, 2019). Biaya variabel proses produksi tiwul instan dapat dilihat pada Tabel 6.

Tabel 6. menunjukan bahwa total biaya variabel yang harus dikeluarkan dalam satu kali proses produksi adalah sebesar Rp. 371.850,-. Biaya Variabel terbesar yang harus dikeluarkan adalah biaya bahan baku sebesar Rp. 195.500.

Berdasarkan Tabel 1. dan Tabel 2. dapat diketahui total biaya untuk produksi tiwul instan dalam satu kali produksi sebesar Rp. 445. 430. Biaya total (total cost) didapatkan dari penjumlahan biaya tetap dan biaya variabel (Nuraini, et. al., 2015) 
Tabel 6. Rata-rata biaya variabel satu kali produksi tiwul instan di Desa Suren Kecamatan Bendungan Kabupaten Trenggalek

\begin{tabular}{llrrr}
\hline No & \multicolumn{1}{c}{ Uraian } & Volume & \multicolumn{1}{c}{$\begin{array}{c}\text { Harga } \\
\text { Satuan } \\
\text { (Rp) }\end{array}$} & \multicolumn{1}{c}{$\begin{array}{c}\text { Jumlah } \\
\text { (Rp) }\end{array}$} \\
\hline 1. & & 1.150 & 195.500 \\
2. & Tenahan baku singkong kerja & $170 \mathrm{~kg}$ & 20.000 & 124.000 \\
3. & Kemasan & $6,2 \mathrm{HOK}$ & 200 & 20.000 \\
4. & Bahan bakar & $100 \mathrm{biji}$ & & 12.350 \\
5. & transportasi & & & 20.000 \\
\hline & Jumlah & & & 371.850 \\
\hline
\end{tabular}

Sumber: Data primer diolah tahun 2019

Produksi, Penerimaan, dan Pendapatan

Produksi merupakan sesuatu yang dihasilkan oleh usaha pengolahan tiwul instan dalam satu kali produksi. Penerimaan usaha merupakan hasil penjualan produksi dengan harga jual
(Mulyadi, 2001). Pendapatan merupakan selisih antara penerimaan dengan total biaya yang dikeluarkan (Hanafie \& Hapsari, 2013). Besarnya produksi, penerimaan dan pendapatan dapat dilihat pada Tabel 7 .

Tabel 7. Produksi, penerimaan dan pendapatan tiwul instan untuk satu kali proses produksi di Desa Suren Kecamatan Bendungan Kabupaten Trenggalek

\begin{tabular}{|c|c|c|}
\hline No & Uraian & Jumlah \\
\hline 1. & Produksi & $100 \mathrm{~kg}$ \\
\hline 2. & Harga & Rp. 6.500 \\
\hline 3. & Penerimaan & Rp. 650.000 \\
\hline 4. & Biaya produksi & Rp. 445.430 \\
\hline 5. & Pendapatan & Rp. 204.370 \\
\hline 6. & R/C Rasio & 1,44 \\
\hline 7. & NPV & 134.927 \\
\hline 8. & IRR (12\%) & $19,98 \%$ \\
\hline 9. & Net B/C Rasio & 1,46 \\
\hline 10. & BEP volume & $69 \mathrm{~kg}$ \\
\hline 11. & BEP harga & Rp. 4.551 \\
\hline 12. & Uji T atas BEP volume & $t_{\text {hit }} 1,835<t_{\text {tab }} 1,943$ \\
\hline 13. & Uji T atas BEP harga & $t_{\text {hit }} 13,505>t_{\text {tab }} 2,015$ \\
\hline
\end{tabular}

Tabel 7. menunjukkan bahwa ratarata hasil produksi tiwul instan dalam satu kali produksi adalah $100 \mathrm{~kg}$ dengan harga jual di tempat penelitian sebesar Rp. $6.500 / \mathrm{kg}$. Jadi total penerimaan yang diperoleh sebesar Rp 650.000 per proses produksi. Pendapatan atau keuntungan yang di terima pengusaha tiwul instan pada satu kali proses produksi sebesar Rp. 204.570.
Analisis Kelayakan

Pengusaha sebagai pelaku usaha mengharapkan produksi usahanya besar dan memperoleh pendapatan yang besar pula. Untuk itu pengusaha menggunakan tenaga dan modal sebagai umpan untuk mendapatkan produksi yang diharapkan. Suatu usaha atau proyek dikatakan berhasil apabila investasi yang ditanam 
pada suatu proyek/usaha tersebut dapat memenuhi kewajiban membayar bunga modal, alat-alat yang digunakan, upah tenaga kerja serta biaya produksi yang lain dan dapat menjaga kelestarian usahanya (Ningsih, 2008).

Untuk mengetahui kelayakan suatu usaha/proyek dapat dianalisis melalui pendekatan analisis Benefit Cost Ratio (B/C), Net Present Value (NPV) dan Internal Rate Of Return (IRR), dengan asumsi bunga bank sebesar $12 \%$. Perhitungan produksi dalam 1 tahun disajikan pada Tabel 8.

Tabel 8. Produksi usaha tiwul instan dalam 1 tahun di Desa Suren Kecamatan Bendungan Kabupaten Trenggalek

\begin{tabular}{rlr}
\hline No & \multicolumn{1}{c}{ Uraian } & Jumlah \\
\hline 1 & Investasi peralatan usaha & Rp. 4.367 .900 \\
2 & Bahan baku & $24.480 \mathrm{~kg}$ \\
3 & Produksi & $14.400 \mathrm{~kg}$ \\
4 & Harga & Rp. 6.500 \\
5 & Penerimaan & Rp. 93.600 .000 \\
6 & Biaya produksi & Rp. 53.546 .400 \\
7 & Pendapatan & Rp. 40.053 .600 \\
8 & NPV & 43.948 .219 \\
9 & IRR (12\%) & 33,10 \\
10 & Net B/C ratio & 1,62 \\
\hline Sumber: Data primer diolah tahun 2019
\end{tabular}

Dengan kapasitas rata-rata satu kali produksi dengan bahan baku singkong segar sebanyak $170 \mathrm{~kg}$ dapat dihasilkan tiwul instan sebanyak $100 \mathrm{~kg}$, kapasitas berjalan satu kali proses per hari selama 12 hari kerja dalam satu bulan. Biaya investasi peralatan usaha sebesar Rp.4.367.900 dan modal kerja Rp. 371.850 sekali proses, dalam satu bulan 12 kali proses. Apabila lama usaha 1 tahun, suku bunga bank diasumsikan $12 \%$ /tahun dan harga tiwul instan Rp 6.500/kg. Dari Hasil analisis menunjukkan, usaha pemanfaatan singkong menjadi tiwul instan menguntungkan dan layak diusahakan. Hal ini ditunjukkan oleh kriteria NPV positif, IRR lebih tinggi dari tingkat suku bunga bank yang berlaku (12\%/tahun) yaitu sebesat 32,92\% dan B/C Rasio > 1 yaitu sebesar 1,62. Hal ini sesuai dengan pernyataan (Elisabeth \& Prasetiaswati, 2018) yang menyatakan bahwa nilai IRR yang melebihi rata-rata tingkat suku bunga yang berlaku di bank menunjukkan jika suatu usaha akan menguntungkan.

Hasil analisis uji t terhadap BEP volume $t_{\text {hit }} 1,835<t_{\text {tab }} 1,943$ artinya tidak berpengaruh nyata, sedangkan uji t atas BEP harga diperoleh $t_{\text {hit }} 13,505>t_{\text {tab }}$ 2,015 , artinya kedua varibel yang dibandingkan berpengaruh signifikan.

\section{KESIMPULAN}

Biaya produksi usaha pengolahan singkong menjadi tiwul instan sebesar Rp. 445.430/proses produksi dengan kapasitas produksi $170 \mathrm{~kg}$ bahan baku singkong dan menghasilkan $100 \mathrm{~kg}$ tiwul instan.

Penerimaan yang didapat dari usaha tiwul instan sebesar Rp. 650.000 dan pendapatan sebesar Rp. 204.570 per satu kali proses produksi Jumlah BEP produksi sebanyak $69 \mathrm{~kg}$, 
sedangkan BEP harga sebesar Rp. $4.551 / \mathrm{kg}$.

Tingkat kelayakan usaha pengolahan tiwul instan di Desa Suren Kecamatan Bendungan Kabupaten Trenggalek menguntungkan dan layak diusahakan karena memiliki nilai NPV positif (43.948.219), nilai IRR lebih besar (33,10\%/tahun) daripada suku bunga bank (12\%/tahun), dan memiliki nilai Net $\mathrm{B} / \mathrm{C}$ ratio lebih dari $1(1,62)$.

\section{DAFTAR PUSTAKA}

Akbar, A. K., \& Febriani, A. kandhita. (2019). Uji Kompresibilitas Granul Pati Singkong dengan Metode Granulasi Basah. Journal of Pharmacy UMUS, 1(1), 7-11.

Badan Pusat Statistik Jawa Timur. (2017). Luas Panen, Produksi, dan Produktivitas Ubi Kayu dan Ubi Jalar Menurut Kabupaten/Kota di Provinsi Jawa Timur. BPS.

Dwiastuti, R. (2017). Metode Penelitian Sosial Ekonomi Pertanian (Cetakan pe). UB Press.

Elisabeth, D. A. anggraeni, \& Prasetiaswati, N. (2018). Kelayakan Finansial dan Nilai Tambah Ubi Kayu di Barito Koala, Kalimatan Selatan. Penelitian Pertanian Tanaman Pangan, 2(2), 129-136. https://doi.org/10.21082/jpptp.v2n2. 2018.p129-136

Elvani, S. (2015). ANALISIS NILAI TAMBAH DAN PENDAPATAN SERTA STRATEGI PENGEMBANGAN PADA AGROINDUSTRI ALEN-ALEN DAN TIWUL INSTAN DI KABUPATEN TRENGGALEK. Universitas Jember.
Hanafie, R., \& Hapsari, T. D. (2013) Kajian Nila Tambah Produk Pangan Olahan Ubi Kayu di Kabupaten Tulungagung. Prosiding Seminar Hasil Penelitian Tanaman Aneka Kacang Dan Umbi, 567-573.

Herawati, E. (2008). Analisis Pengaruh Faktor Produksi Modal, Bahan Baku, Tenaga Kerja Dan Mesin Terhadap Produksi Glycerine Pada $P T$. Flora. Universitas Sumatera Utara.

Herawati, N. (2013). Analisis pengaruh pendidikan, upah,pengalaman

kerja,jenis kelamin dan umur terhadap produktivitas tenaga kerja industri shutllecock Kota Tegal (Vol. 53, Issue 9) [Universitas Diponegoro Sembarang]. https://doi.org/10.1017/CBO978110 7415324.004

I, H. K. M. W. L., \& Playen, K. (2019). THE BENEFITS OF CASSAVA IN FULFILLING COMMUNITY FOREST FARMER' S. 136-147. https://doi.org/10.30598/jhppk.

Lambajang, A. A. A. (2013). Analisis Perhitungan Biaya Produksi Menggunakan Metode Variabel Costing Pt. Tropica Cocoprima. Jurnal Riset Ekonomi, Manajemen, Bisnis Dan Akuntansi, 1(3), 673683.

Mahayasa, I. B., \& Yuliarmi, N. N (2018). engaruh Modal, Teknologi, dan Tenaga Kerja Terhadap Produksi dan Pendapatan Usaha Kerajinan Ukiran Kayu di Kecamatan Tembuku Kabupaten Bangli. E-Jurnal EP Unud, 6(8).

Mahendra, A. D. (2014). Analisis 
Pengaruh Pendidikan, Upah, Jenis Kelamin, Usia Dan Pengalaman Kerja Terhadap Produktivitas Tenaga Kerja (Studi di Industri Kecil Tempe di Kota Semarang). In Skripsi.

Mardliyah, A., \& Supriyadi. (2018). Kelayakan Finansial Usaha Pengolahan Ubi Kayu Menjadi Tiwul Instan di Desa Wonosari Kecamatan Pekalongan Kabupaten Lampung Timur. Jurnal Penelitian Pertanian Terapan, 18(1), 1-6. https://doi.org/10.25181/jppt.v18i1.3 30

Mulyadi. (2001). Akuntansi Manajemen (Edisi Keti). Salemba Empat.

Mulyadi. (2003). Ekonomi Sumber Daya Manusia Dalam Perspektif Pembangunan. PT. Raja Grafindo Persada.

Ningsih, G. M. (2008). Analisis Nilai Tabah dan Penerimaan Agroindustri Tiwul Instan di Malang Selatan. Tropika, 16(1), 88-98.

Nuraini, F., Nawasnsih, O., \& Sitanggang, M. M. (2015). Analisis Finansial dan Sensitivitas Usaha Kecil Menengah Dodol Coklat. Jurnal Penelitian Pertanian Terapan, 15(3).

Putri, B. A. S. (2020). Pengaruh Modal, tenaga Kerja, dan Bahan Baku terhadap Nilai Produksi. universitas Negeri Semarang.

Riyanto, B. (2001). Dasar-Dasar Perusahaan. Yayasan Penerbit Yogyakarta.

Soekartawi. (2006). Agroindustri dalam
Perspektif Sosial Ekonomi. Raja Grafindo Persada.

Suhardi, \& Suharjo. (2006). Teknologi Produksi Tiwul Instan dari Tepung Ubi kayu Komposit. Balai Pengkajian Teknologi Pertanian.

Turere, V. N. (2013). Pengaruh Pendidikan dan Pelatihan Terhadap Peningkatan Kinerja Karyawan pada Balai Pelatihan Teknis Pertanian Kalasey. Jurnal EMBA, 1(3), 10-19. https://doi.org/10.17509/image.v7i1. 23137

Utami, N. S., \& Adita, M. D. (2019). Pengenalan Analisis Break Even Point (BEP) Sebagai Bekal bagi Mahasiswa Ilmu dan Teknologi Pangan Dalam Menumbuhkan Jiwa wirausaha. Randang Tana: Jurnal Pengabdian Masyarakat, 2(1), 5460.

Winarsih, Baedhowi, \& Bandi. (2014). Pengaruh Tenaga Kerja, Teknologi dan Modal dalam Meningkatkan Produksi di Industri Pengolahan Garam Kabupaten Pati. Jurnal Pendidikan Insan Mandiri. 